\title{
PERANCANGAN SISTEM INFORMASI PARIWISATA KOTA SORONG MENGGUNAKAN WEB DAN LINE@ CHATBOT SEBAGAI MEDIA INFORMASI PARIWISATA
}

\author{
Muhammad sahid s kadaton ${ }^{1}$, Rendra Soekarta ${ }^{2}$, \\ ${ }^{1,2}$ Fakultas Teknik Program Studi Teknik Informatika Universitas Muhammadiyah Sorong
}

kadatonsahid@gmail.com

\begin{abstract}
Sorong is one of the cities surrounded by natural objects and is very strategically located as the gateway to Papua and West Papua so the flow of information and business is very smooth here. But in reality there are still many domestic tourists who have not really gotten information about local products or souvenirs, and the tourism industry in Sorong City. Therefore tourists need information that can be easily obtained regarding the tourism of the city of Sorong so that tourism in the city of Sorong can develop well and have an impact on the revenue of the city of Sorong in the tourism sector. then the author wants to implement a chatbot that can provide information about Sorong city tourism, using the line chat bot service as a medium for delivering information on tourist attractions that can be interactive and line webhook maker services as chat design services on bots with interaction methods using keywords to select categories and location of tourist attractions.
\end{abstract}

Keyword: Design, System, Information, tourism, line cahtbot

\begin{abstract}
Abstrak
Sorong merupakan salah satu kota yang di kelilingi objek wista alam dan berlokasi sangat strategis yaitu sebagai pintu gerbang Papua dan Papua Barat sehingga arus informasi juga bisnis sangat lancar disini. Tetapi kenyataannya masih banyak wisatawan domestik yang belum benar-benar mendapatkan informasi tentang produk lokal atau souvenir, dan industri pariwisata di Kota Sorong. Oleh karena itu wisatawan membutuhkan informasi yang bisa di dapat dengan mudah mengenai pariwisata kota sorong sehingga pariwisata yang ada di kota sorong dapat berkembang dengan baik dan berdampak pada pendapatan kota sorong di bidang pariwisata. maka Penulis ingin menerapkan sebuah chatbot yang dapat memberikan informasi seputar pariwisata kota sorong, dengan mengunakan layanan line chat bot sebagai media penyampaian informasi tempat wisata yang bisa interatif dan layanan line webhook maker sebagai layanan perancangan chat pada botnya dengan metode interaksi mengunakan keyword untuk memilih kategori dan lokasi tempat wisata.
\end{abstract}

Keyword : Perancangan, Sistem, Informasi, pariwisata, line cahtbot

\section{Pendahuluan}

Sorong merupakan salah satu kota yang di kelilingi objek wista alam dan berlokasi sangat strategis yaitu sebagai pintu gerbang Papua dan Papua Barat sehingga arus informasi juga bisnis sangat lancar disini. Tetapi kenyataannya masih banyak wisatawan domestik yang belum benar-benar mendapatkan informasi tentang produk lokal atau souvenir, dan industri pariwisata di Kota Sorong sehinga membuat kota sorong hanya sebagai kota transit dimana wisatawan hanya singgah dan langsung pergi ke tampat tujuan wiasata selajutnya yang berada di luar kota sorong, contoh masalahnya wisatawan hanya mampir dan langsung bergegas ke Raja ampat, tanpa mereka ketahui bahwa di kota sorong juga memiliki tempat wisata alam yang tidak kalah menarik untuk menjadi tujuan wisata favorit mereka. Karena kurangnya informasi mengenai dimana obyek daerah tujuan seperti wisata favorit di kota sorong, tempat menginap di kota sorong, kuliner yang khas di kota sorong, dan produk lokal atau souvenir yang ada dikota sorong. Sehingga wisatawan tidak dapat mengetahui kemana tujuan wisata mereka di kota sorong yang membuat liburan mereka menjadi sia-sia karena telah meluangkan waktu, biaya, tenaga. Dan membuat kota sorong hanya sebagai kota transit karena kurangnya informasi pariwisata.

Oleh karena itu wisatawan membutuhkan informasi yang bisa di dapat dengan mudah mengenai pariwisata kota sorong sehingga pariwisata yang ada di kota sorong dapat berkembang dengan baik dan berdampak pada pendapatan kota sorong di bidang pariwisata.

\section{Kerangka Teori \\ 2.1 Bot}

Bot merupakan program komputer yang melakukan suatu proses yang telah ditentukan oleh programmer secara otomatis. Program ini dilakukan pada wilayah-wilayah yang ditentukan berdasarkan ketentuan yang dibuat oleh programmer (I Made Adi Susilayasa \& I Gede Oka Gartria Atitama, 2017) 


\subsection{Line}

Line adalah sebuah aplikasi pengirim pesan instan gratis yang dapat digunakan pada berbagai platform seperti telepon cerdas, tablet, dan komputer. LINE difungsikan dengan menggunakan jaringan internet sehingga pengguna LINE dapat melakukan aktivitas seperti mengirim pesan teks, mengirim gambar, video, pesan suara, dan lain lain. LINE diklaim sebagai aplikasi pengirim pesan instan terlaris di 42 negara.

Untuk mendukung perkembangan chatbot, LINE tidak hanya menyediakan messeging API lengkap dengan dokumentasinya, melainkan juga memberikan SDK untuk beberapa bahasa pemrograman diakun GitHubnya. Diantaranya adalah Java, PHP, Ruby, Go, Perl dan Python. SDK atau LINE Software Development Kit adalah library atau package yang dapat digunakan oleh developer untuk menggunakan Messaging API. Dengan menggunakan SDK, developer dapat langsung menerapkan method-method terkait API tanpa harus membuat dari nol. Selain itu ketika ada pembaharuan API dari LINE, developer hanya perlu memperbaharui SDK sehingga meminimalisir perubahan basis kode pada aplikasi.

API Messaging memungkinkan data dilewatkan antara server aplikasi bot dan Platform LINE. LINE platform akan mengirimkan informasi ke server kita setiap kali ada interaksi antara pengguna dengan akun kita, secara tidak langsung Messaging API ini sebagai jembatan untuk LINE platform dengan aplikasi chatbot. Ada dua jenis interaksi, yakni:

1. Pengguna mengirimkan pesan

2. Pengguna melakukan sebuah aksi, seperti menjadikan akun bisnis sebagai teman

Informasi dikirim dalam format JSON melalui protokol HTTPS ke URL yang sudah didaftarkan sebagai webhook. Struktur data JSON yang dikirim akan bervariasi tergantung dari jenis pesan atau operasi. Setiap request menyertakan kode access token yang digunakan untuk memverifikasi bahwa request yang diterima adalah benar-benar dari platform LINE. Jika access token tidak dikenali, maka request dianggap tidak valid (Dimas Pratama Jati \& Muhammad Rifqi Ma'arif, 2018).

\subsection{Line webhook maker}

Webhook merupakan sebuah server yang digunakan untuk menerima request dan mengirimkan response kepada komponen-komponen lainnya yang melakukan request ke server webhook ini. Informasi dikirim dalam format JSON melalui protokol HTTPS ke URL yang sudah didaftarkan sebagai webhook. Struktur data JSON yang dikirim akan bervariasi tergantung dari jenis pesan atau operasi. Setiap request menyertakan kode access token yang digunakan untuk memverifikasi bahwa request yang diterima adalah benar-benar dari platform LINE. Jika access token tidak dikenali, maka request dianggap tidak valid. aplikasi chatbot pada platform Line, ditunjukkan oleh Gambar 1. Komponen lainnya yang dimaksudkan disini adalah komponen seperti layanan Line dan layanan Line webhook maker agar dapat melakukan komunikasi antar satu layanan dengan layanan lainnya. Di sini penulis mengunakan webhook pada layanan Line webhook maker (Ahmad siwandi, 2018) Line webhook maker Adalah layanan berbasis web yang dapat desain chatbot dengan mengunakan fitur yang di sediakan di dalam web tersebut diantaranya ada type text, type sticker, type image, type video, type audio, type loction, type button, type confirm, type carousel 1 button, type carousel 2 button, type carousel 3 button, dan sekaligus membuat Webhook URL untuk menghubungkan Bot pada aplikasi LINE dengan layanan line webhook maker. penulis mengunakan layanan webhook maker untuk mendesain tampilan chatbotnya atau alur berinteraksi mengunakan keyword.

\subsection{Model pengembangan waterfall}

SDLC (System Development Life Cycle) Menurut Sukamto dan Shalahuddin (2013:26) mengemukakan bahwa " SDLC atau Software Development Life Cycle atau sering disebut juga System Development Life Cycle adalah proses mengembangkan atau mengubah suatu sistem perangkat lunak dengan menggunakan model-model dan metodologi yang digunakan orang untuk mengembangkan sistemsistem perangkat lunak sebelumnya, berdasarkan best practice atau cara-cara yang sudah teruji baik."

Penulis mengunakan pengembangan sistem SDLC model waterfall sebagai tahapan penelitian agar menjadi terstruktur dan sistematis dalam metode ini meliputi perencanaan sistem, analisa sistem, peracangan sistem, implementasi sekaligus pengujian, dan pemeliharaan. Model metode waterfall dapat dilihat pada gambar 2.1 .

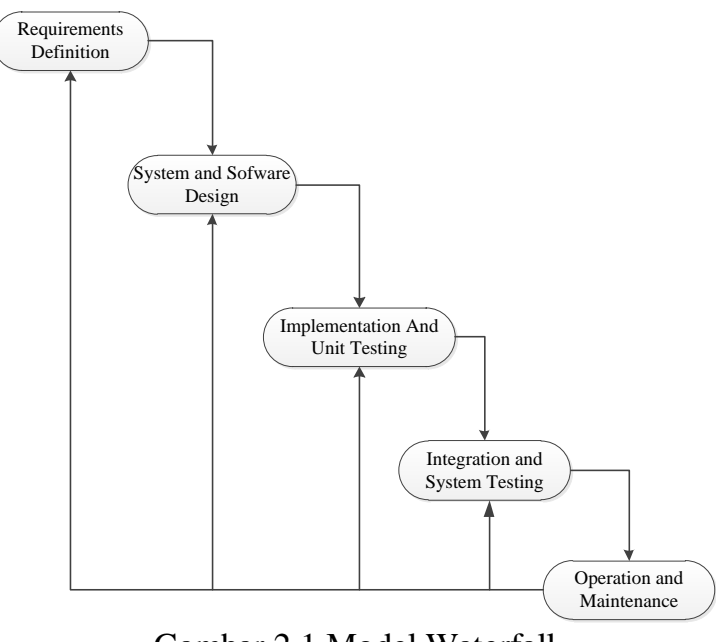

Gambar 2.1 Model Waterfall

Sumber(sukamto\&shalahudin,2013)

\section{Metodologi}

\subsection{Bagan alir penelitian}

Struktur tahapan penilitian di bentuk dengan tujuan mengoptimalkan proses penilitian agar lebih teratur 
dan sistematis. Berikut gambar struktur tahapan penilitian yang di buat oleh penulis dalam melakukan penilitian.

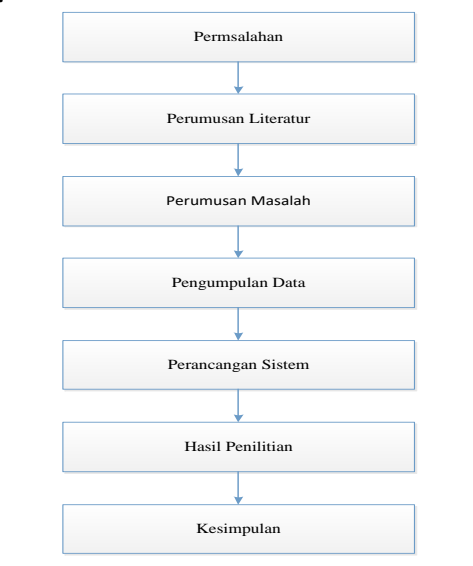

Gamabar 3.1 Bagan alir penelitian

\subsection{Metode Dengumpulan Data}

Penulis dalam penelitianya menggunakan 3 cara untuk mengumpulkan data, yaitu, observasi dan dokumentasi.
1. Studi pustaka
2. Observasi
3. Dokumentasi

\subsection{Analisa Kebutuhan}

Tahapan analisa sistem ini dilakukan untuk memenuhi kebutuhan sistem yang mampu memberikan informasi tentang produk lokal, dan industri pariwisata kepada wisatawan lokal dan wisatawan macanegara secara interaktif. Pada sistem baru ini dibuatlah sistem informasi pariwisata kota sorong mengunakan LINE@CHATBOT sebagai media informsasi tempat wisata.

\subsection{Desain Sistem}

Pada tahap ini membuat sebuah rancangan program input dan output yang berupa chatbot. Pembuatan sistem dapat dimulai setelah melihat dan mencari apa yang dibutuhkan chatbot untuk menginformasikan pariwisata kota sorong. Dari kebutuhan sistem tersebut akan di terapkan ke dalam sistem yang akan dibuat. Desain chatbot yang akan di buat yaitu, data infomasi hotel, toko souvenir, kuliner dan tempat wisata. Denga mengunakan tampilan carousel 1 button, carousel 3 button dan location. Yang telah di sediakan oleh platform line.

\section{5 implementasi chatbot}

Setelah pembuatan peracangan sistem maka langkah selanjutnya adalah mengimplementasikan hasil perancangan kedalam program yang akan di buat. Selanjutnya setelah program selesai maka dilanjutkan dengan melakukan uji coba chatbot yang telah di buat pada telepon pintar / smart phone. Implementasi hasil perancangan dalam bentuk chatbot meliputi informasi pariwisata kota sorong yaitu 5 hotel, 5 toko souvenir, 5 kuliner dan 5 tempat wisata.

\subsection{Pengujian}

Melakukan pengujian untuk mengetahui kesalahan dan trouble yang mungkin terjadi, sampai dipastikan chatbot berjalan dengan baik. pengujian yang akan dilakukan yaitu dengan mencoba setiap keyword dan tombol pada carousel yang ada pada chatbot apakah dapat berjalan sesuai dengan baik atau masih ada kesalahan yang terjadi.

\subsection{Pemeliharaan}

Tahap ini dilakukan setelah proses evaluasi chatbot menunjukan hasil yang bagus tanpa ada kesalahan atau truoble pada program. Tahap ini merupakan tahapan pemeliharaan terhadap program atau chatbot yang telah penulis buat.

\subsection{Arsitektur sistem chatbot}

Berikut ini adalah tabel proses alur chatbot yang penulis buat untuk dapat memahami alur berjalan chatbot dan sekaligus arsitektur chatbotnya yang ditunjukan pada tabel 3.1

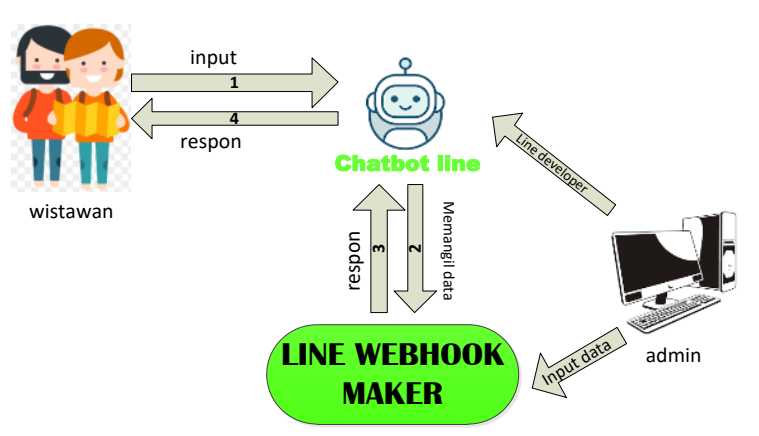

Gambar 3.2 arsitektur chatbot

Tabel 3.1 proses alur chatbot

\begin{tabular}{|c|c|c|}
\hline $\begin{array}{l}\text { Pros } \\
\text { es }\end{array}$ & Keterangan & Admin \\
\hline 1 & $\begin{array}{l}\text { Wisatawan harus } \\
\text { mempunyai aplikasi line } \\
\text { dan menambahkan bot } \\
\text { sebagai teman, selanjutnya } \\
\text { menginputkan pertanyaan } \\
\text { sesuai keyword }\end{array}$ & \multirow{3}{*}{$\begin{array}{l}\text { Menginputka } \\
\mathrm{n} \text { data } \\
\text { informasi } \\
\text { pariwisata } \\
\text { sekaligus } \\
\text { mendesain } \\
\text { chat pada line } \\
\text { webhook } \\
\text { maker, dan } \\
\text { pada line } \\
\text { developer } \\
\text { untuk } \\
\text { membuat } \\
\text { botnya }\end{array}$} \\
\hline 2 & $\begin{array}{l}\text { Chatbot memangil data ke } \\
\text { line webhook maker selaku } \\
\text { pihak ke dua dan } \\
\text { memperoses pertanyaan } \\
\text { dengan menyamakan } \\
\text { pertanyaan } \\
\text { keyword yang sudah } \\
\text { penulis inputkan }\end{array}$ & \\
\hline 3 & $\begin{array}{l}\text { Line webhook maker telah } \\
\text { selesai memproses dan } \\
\text { memberikan respon seputar } \\
\text { informasi pariwisata yang } \\
\text { wisatawan tanyakan }\end{array}$ & \\
\hline
\end{tabular}




\begin{tabular}{|l|l|l|}
\hline 4 & $\begin{array}{l}\text { Chatbot telah mendapatkan } \\
\text { respon dari line webhook } \\
\text { maker berupa informasi }\end{array}$ \\
pariwisata r untuk & selanjutnya bot membalas \\
pesan wisatawan & \\
\hline
\end{tabular}

\subsection{Alat dan Bahan}

Analisa kebutuhan (hardware)

Kebutuhanh perangkat keras yang digunakan untuk pengembangan sistem chatbot antara lain :
a. Computer /laptop
b. Internet
c. Smartphone

\section{Analisa kebutuhan (software)}

Kebutuhan perangkat lunak yang digunakan untuk pengembangan sistem chatbot antara lain :
a. Sistem operasi windows 7
b. Aplikasi browser google crom

c. Website https://account.line.biz/login \& https://line.farzain.com

d. Aplikasi LINE Business Center, LINE Bot Designer Setup 1.0.0

\section{Hasil dan Pembahasan \\ 4.1 implementasi dan pengujian}

Bahasan dalam tahapan ini meliputi implementasi dan pengujian sistem. Implementasi dan pengujian sistem ini dilakukan untuk mengetahui apakah sistem yang telah dibangun sudah bekerja sesuai dengan rancangan sistem. Pengujian sistem dilakukan dengan menggunakan metode black-box testing. Metode ini digunakan untuk melakukan pengujian yang berfokus pada keluaran yang dihasilkan dari proses masukan yang terjadi. Penulis menginplementasikan sekaligus menguji chatbot dengan mengunakan telepon pintar/ smartphone yang sebelumnya telah diinstal aplikasi LINE.

Pada tahapan ini, penulis akan melakukan pengujian terhadap chatbot yang telah dibuat sebelumnya untuk memeriksa apakah keluaran atau response yang diberikan akan sesuai dengan yang telah ditentukan sebelumnya. Pengujian dilakukan ke dalam dua tugas. Di antaranya adalah kemampuan chatbot untuk menjawab keyword dari user untuk menampilkan informasi tempat wisata dan lokasi tempat wisata. Pada saat user pertama kali berinteraksi dengan chatbot, user akan disambut dengan pesan pembuka di dalam aplikasi Line, seperti yang ditunjukkan pada Gambar 4.1.

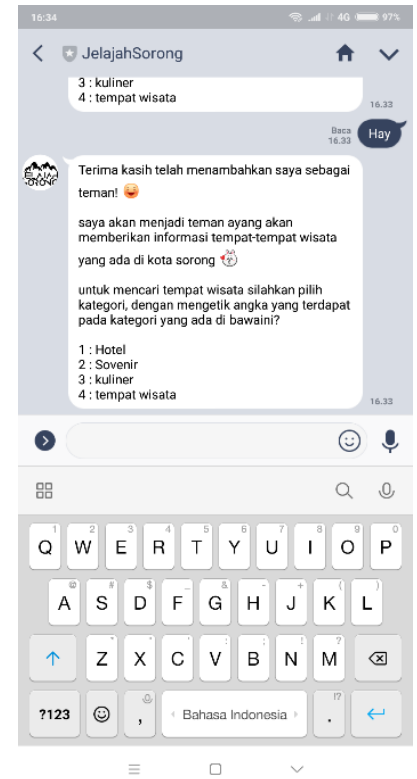

Gambar 4.1 pesan greeting

Tabel 4.1 pengujian pesan pembuka

\begin{tabular}{|c|c|c|}
\hline $\begin{array}{l}\text { Scenario } \\
\text { pengujian }\end{array}$ & $\begin{array}{l}\text { Output yang di } \\
\text { harapkan }\end{array}$ & Output hasil \\
\hline $\begin{array}{l}\text { Pesan saat } \\
\text { penguna baru } \\
\text { menambahkan } \\
\text { sebagai teman / } \\
\text { add chatbot } \\
\text { line. }\end{array}$ & $\begin{array}{l}\text { Chatbot } \\
\text { memberikan } \\
\text { respon dengan } \\
\text { menawarkan } \\
\text { beberapa } \\
\text { keyword untuk } \\
\text { menjadi bahan } \\
\text { Tanya. }\end{array}$ & $\begin{array}{l}\text { Valid } \\
\text { (chatbot } \\
\text { merespon) }\end{array}$ \\
\hline $\begin{array}{l}\text { Pesan saat } \\
\text { penguna baru } \\
\text { menambahkan } \\
\text { sebagai teman / } \\
\text { add chatbot } \\
\text { line tidak } \\
\text { sesuai dengan } \\
\text { keyword. }\end{array}$ & $\begin{array}{l}\text { Chatbot } \\
\text { memberikan } \\
\text { respon dengan } \\
\text { menawarkan } \\
\text { ulang beberapa } \\
\text { keyword untuk } \\
\text { menjadi bahan } \\
\text { Tanya, atau } \\
\text { berupa auto } \\
\text { replay } \\
\text { message. } \\
\text { Karena } \\
\text { mengisikan } \\
\text { pertanya selain } \\
\text { keyword. }\end{array}$ & $\begin{array}{l}\text { Valid } \\
\text { (chatbot } \\
\text { merespon } \\
\text { dengan } \\
\text { menawarkan } \\
\text { keyword } \\
\text { berulang kali } \\
\text { ) }\end{array}$ \\
\hline
\end{tabular}

Pengujian selanjutnya membahas tentang keyword "1" atau kategori hotel yang ditunjukan pada gambar 4.2 . 


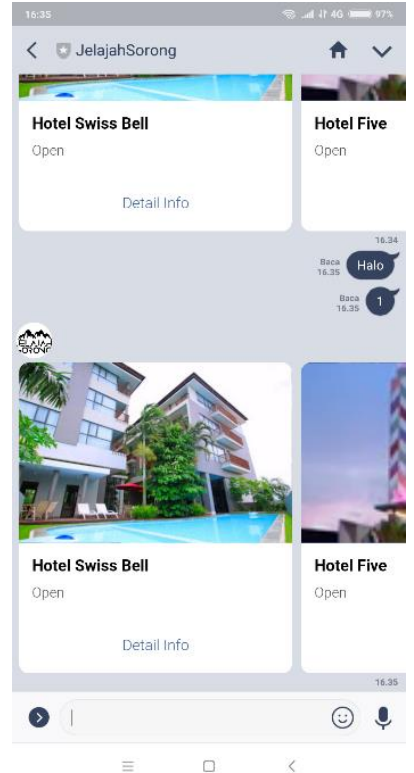

Gambar 4.2 kategori hotel

Tabel 4.9 pengjian kategori hotel.

\begin{tabular}{|c|c|c|}
\hline $\begin{array}{l}\text { Scenario } \\
\text { pengujian }\end{array}$ & $\begin{array}{l}\text { Output yang di } \\
\text { harapkan }\end{array}$ & $\begin{array}{l}\text { Output } \\
\text { hasil }\end{array}$ \\
\hline $\begin{array}{l}\text { User akan } \\
\text { mengikuti } \\
\text { intruksi yang } \\
\text { telah di berikan } \\
\text { sebelumnya } \\
\text { dengan } \\
\text { mengunakan "1" } \\
\text { keyword "l } \\
\text { berupa kategori } \\
\text { hotel }\end{array}$ & $\begin{array}{l}\text { Chatbot } \\
\text { memberikan } \\
\text { respon dengan } \\
\text { menawarkan } \\
\text { beberapa hotel } \\
\text { yang ada di kota } \\
\text { sorong berupa tipe } \\
\text { carousel yang bisa } \\
\text { di scroll secara } \\
\text { horizontal. }\end{array}$ & $\begin{array}{l}\text { Valid } \\
\text { (chatbot } \\
\text { merespon) }\end{array}$ \\
\hline $\begin{array}{lr}\text { User } & \text { akan } \\
\text { mengklik } & \text { Pada } \\
\text { button } & \text { detail } \\
\text { info } & \text { untuk } \\
\text { melihat } & \text { info } \\
\text { hotel } & \text { berupa } \\
\text { website } & \text { hotel } \\
\text { tersebut. } & \\
\end{array}$ & $\begin{array}{l}\text { Chatbot } \\
\text { memberikan } \\
\text { respon dengan } \\
\text { membukaa } \\
\text { website hotel } \\
\text { swiss bel. }\end{array}$ & $\begin{array}{l}\text { Valid } \\
\text { (chatbot) }\end{array}$ \\
\hline
\end{tabular}

Selanjutnya ada kategori tempat wisata yang mempunyai keyword "4" yang tampilannya bertipe carousel button 3 yang dimana ketiga button tersebut diberi nama "detail info","detail lokasi",dan “deskripsi”. Seperti yang ditunjukan pada gambar 4.3.

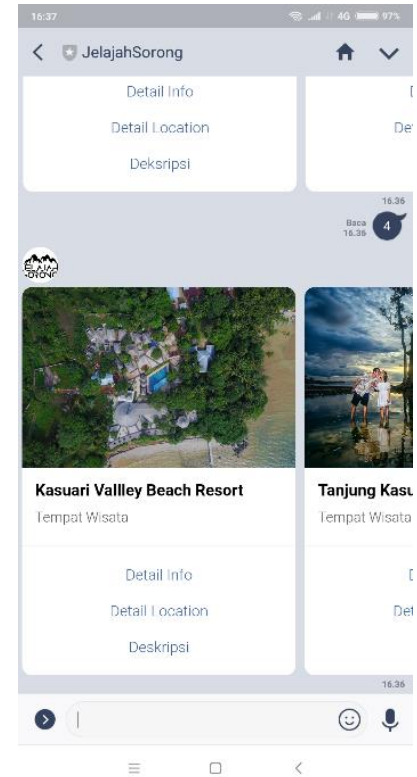

Gambar 4.3 kategori tempat wisata

Pada saat user mengklik button "detail info" user akan masuk pada situs website tempat wisata tersebut sama seperti kategori hotel sebelumnya, pada saat user mengklik button "detail lokasi" chatbot akan menampilkan keyword nama lokasi, user di intruksikan untuk mengketik nama lokasi tempat wisata sesuai denga keyword yang chatbot berikan setalah itu lokasi tempat wisata yang berupa tipe lokasi di tampilkan seperti yang ditunjukan seperti pada gambar 4.4 .

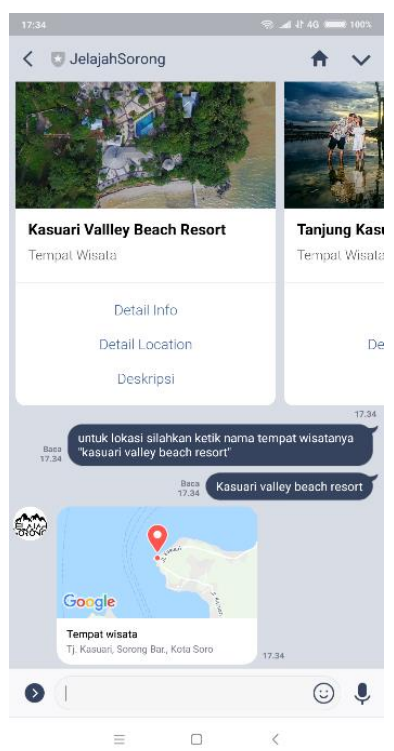

Gambar 4.4 lokasi tempat wisata

Tabel 4.2 pengujian tempat wisata

\begin{tabular}{|l|l|l|}
\hline $\begin{array}{l}\text { Scenario } \\
\text { pengujian }\end{array}$ & $\begin{array}{l}\text { Output yang di } \\
\text { harapkan }\end{array}$ & $\begin{array}{l}\text { Output } \\
\text { hasil }\end{array}$ \\
\hline
\end{tabular}




\begin{tabular}{|c|c|c|}
\hline $\begin{array}{l}\text { User akan } \\
\text { mengikuti } \\
\text { intruksi yang } \\
\text { telah di berikan } \\
\text { sebelumnya } \\
\text { dengan } \\
\text { mengunakan "4" } \\
\text { keyword "4 } \\
\text { berupa kategori } \\
\text { tempat wisata }\end{array}$ & $\begin{array}{l}\text { Chatbot } \\
\text { memberikan } \\
\text { respon dengan } \\
\text { menawarkan } \\
\text { beberapa tempat } \\
\text { wisata yang ada di } \\
\text { kota sorong } \\
\text { berupa tipe } \\
\text { carousel yang } \\
\text { bisa di scroll } \\
\text { secara horizontal. }\end{array}$ & $\begin{array}{l}\text { Valid } \\
\text { (chatbot } \\
\text { merespon) }\end{array}$ \\
\hline $\begin{array}{lr}\text { User } & \text { akan } \\
\text { mengklik Pada } \\
\text { button detail info } \\
\text { untuk melihat } \\
\text { infor tempat } \\
\text { wisata berupa } \\
\text { website tempat } \\
\text { wisata tersebut. }\end{array}$ & $\begin{array}{l}\text { Chatbot } \\
\text { memberikan } \\
\text { respon dengan } \\
\text { membukaa } \\
\text { website tempat } \\
\text { wisata tersebut. }\end{array}$ & $\begin{array}{l}\text { Valid } \\
\text { (chatbot) }\end{array}$ \\
\hline $\begin{array}{lr}\text { User } & \text { akan } \\
\text { mengklik } & \text { Pada } \\
\text { button } & \text { lokasi } \\
\text { untuk melihat } \\
\text { lokasi tempat } \\
\text { wisata berupa } \\
\text { google map. }\end{array}$ & $\begin{array}{l}\text { Chatbot } \\
\text { memberikan } \\
\text { respon dengan } \\
\text { membuka google } \\
\text { map tempat } \\
\text { wisata tersebut. }\end{array}$ & $\begin{array}{l}\text { Valid } \\
\text { (chatbot) }\end{array}$ \\
\hline $\begin{array}{l}\text { User akan } \\
\text { mengklik Pada } \\
\text { button deskripsi } \\
\text { untuk } \\
\text { menampilkan } \\
\text { deskripsi. tempat } \\
\text { wisata berupa } \\
\text { text. }\end{array}$ & $\begin{array}{l}\text { Chatbot } \\
\text { memberikan } \\
\text { respon dengan } \\
\text { membuka } \\
\text { deksripsi tempat } \\
\text { wisata tersebut. }\end{array}$ & $\begin{array}{l}\text { Valid } \\
\text { (chatbot) }\end{array}$ \\
\hline
\end{tabular}

\section{Kesimpulan dan saran}

Berdasarkan hasil penelitian yang di lakukan terhadap PERANCANGAN SISTEM INFORMASI PARIWISATA KOTA SORONG MENGUNAKAN LINE@CHATBOT SEBGAI ALAT INFORMASI PARIWISATA dan pembahasannya yang telah di lakukan, maka dapat disimpulkan bahwa:

a. Telah berhasil dibuat sistem chatbot yang dapat menginformasikan tentang pariwisata yang ada di kota sorong sesuai dengan sesuai dengan kebutuhan informasih. Sistem chatbot ini dapat digunakan untuk menginformasikan tempat destinasi wisata dan lokasi dengan tepat.

b. Chatbot yang dibuat untuk wistawan ini dapat berkomunikasi dengan mengunakan platform pesan gratis yaitu aplikasi LINE. Yang mempu berkomunikasi dengan user mengunakan keyword yang telah penulis rancang dengan mengunakan layanan line webhook maker sekaligus mendesain chat tampilan informasi pariwisata kota sorong. c. Chatbot telah dibuat saling terhubung antar platform line developer dan line webhook maker. dengan mengunakan webhook.

d. Chatbot dibuat ini kedepanya bisa membantu dalam memenuhi informasi yang wisatawan perlukan dan sekaligus membuat "JELAJAH SORONG" sebagai platform baru yang dapat menginformasikan destinasi pariwisata kota sorong melalui media teknologi informasi.

\section{Saran}

Berdasarkan pembahan dan pengujian yang telah dilakukan, sistem pada chatbot ini masih memiliki beberapa kekurangan, dapat diperbaiki kedepanya sehingga dapat meningkatkan kinerja aplikasi menjadi lebih maksimal dalam penggunaannya. Untuk pengembangan penelitian sistem ini lebih lanjut. Ada beberapa saran yang penulis buat untuk dapat diperhatikan.

a. Sistem chatbot masih memiliki kekurangan dalam berinteraksi yaitu masih mengunakan keyword untuk berinteraksi. Sehingga kedepanya dapat dirancang sistem yang dapat berinteraksi layaknya dapat menjawab semua pertanyan dari user.

b. Chatbot yang dibuat menginformasikan pariwisata baru 5 kategori yaitu Hotel, Kuliner, Sovenir, dan tempat wisata. Sehingga kedepanya dapat di tembahkan lagi agar bisa menjadi sistem infotmasi yang luas.

c. Chatbot dapat dikembangkan dengan menggunakan platform pesan gratis lain yang populer seperti. Telegram, whasapp, messenger(Facebook) dan lainya. Sehingga mampu menjangkau wisatawan yang berbagai macam platform pesan gratis lainya.

\section{Ucapan Terima Kasih}

Bismillahirrahmnirrahim.

Assalamualaikum Wr. Wb.

Puji sukur dipanjatkan kepada alloh subhanahu wa ta'ala sehingga tugas akhir ini dapat di selesaikan. Tugas akhir ini di ajukan untuk memenuhi salah satu persyaratan memperoleh derajat kesarjanaan sastra-1 pada program studi teknik informatika universitas muhammadiyah sorong. Tugas akhir ini di beri judul Perancangan Sistem Informasi Pariwisata Kota Sorong Mengunakan Aplikasi Line@ Chatbot Sebagai Sebagai Media Informasi Pariwisata.

Penyusun mengucapkan terima kasih kepada semuah pihak yang telah membantu dalam menyelesaikan tugas akhir ini. Ucapan tersebut di ajukan kepada:

1. Bapak Rendra soekarta, S.Kom., M.T. selaku ketua program studi teknik informatika universitas muhammdiyah sorong.

2. Bapak Teguh Hidayat Iskandar Alam, S.Kom, M.MT. selaku dosen pembimbing pertama 
3. Bapak Ir Irman Amri, S.T., MT dosen pembimbing ke dua.

4. Bapak Radit Faisal Waliulu S.Kom,.M.T. Selaku dosen penguji

5. Orang tua tercinta, kaka, adik, serta temanteman yang telah memberikan dorongan dan masukan kepada penyusun.

Akhir kata semoga tugas akhir ini dapat bermanfaat bagi rekan-rekan mahasiswa pada umumnya dan penyusun pada khususnya.

\section{Daftar Pustaka}

Ahmad iswandi (2018). Implementasi chatbot pada order management system usaha mikro kecil menengah. (TA No.13523227/2014). Unpublished, universitas islam Indonesia, Yogyakarta.

Ananda dwi R, Firdha imamah, Yusuf mei andres S, Ardiansyah (2018) aplikasi chatbot (MILKI BOT) yang terintegrasi dengan WEB CMS untuk customer service pada UKM MINSU. Jurnal cendekia Vol. XVI cendekia 2018

Andre Hermawan1, Moehammad Awaluddin2, Bambang Darmo Yuwono3, (2017 Oktober) Pembuatan Aplikasi Webgis Informasi Pariwisata Dan Fasilitas Pendukungnya Di Kabupaten Kudus. Jurnal Geodesi Undip (Vol 6, Nomor 4). 51-59.

Arsad (2011) Perancangan Sistem Informasi Pariwisata Berbasis Web Di Dinas Kebudayaan Dan Pawisata Kabupaten Muna. Universitas Islam Negeri Syarif Hidayahtullah Jakarta.

Darius Zumstein1 And Sophie Hundertmark2 (2017, November ). Chatbots - An Interactive Technology For Person. Iadis International Journal On Www/Internet Vol. 15, No. 1, Pp. 96-109

Dhebys Suryani1, Eka Larasati Amalia2 (2017, Oktober). Aplikasi Chatbot Objek Wisata Jawa Timur Berbasis Aiml. Smartics Journal (Vol. 3, No. 2.) 47-54.

Dimas pratama jati, Muhammad rifqi ma'arif. (2018). the development of chatbot application on line messaging platform for custumer service in jogja sewa kamera. Jurnal volume 7, nomor 2, November 2018

Dwi Mustika Kusumawardani (2013). Sistem Informasi Pariwisata Pada Abupaten Malang Berbasis Android. Naskah Publikasi Sekolah Tinggi Manajemen Informatika Dan Komputer Amikom Yogyakarta Yogyakarta.
I made Adi Susilaya1, I Gede Oka Gartria Atitama (2017) implementasi Line chat bot rekomendasi wisata mengunakan platform as a sevice, internet of things (IOT) \& big data: teknologi, tantangan dan peluang bali, 28 juli 2017.

Indra Permana1, Deni Ahmad Jakaria2, (2018) Aplikasi Dan Panduan Angkutan Kota Tasikmalaya Berbasis Android. Jumantaka Vol 1. No. 1 (2018) 291 - 300,

Joko Dewanto (2004,Maret). System Development Life Cycle Dengan Beberapa Pendekatan. Jurnal Fasilkom (Vol.2 No.1). 39-47.

Rintha Prasetyo Nur Sukma Hendra Ningsih (2011). Sistem Informasi Pariwisata Daerah Kabupaten Wonogiri Berbasis Web. Universitas Sebelas Maret.

Soekarta, R. (2015). RANCANGAN BANGUN SISTEM AKADEMIK BERBASIS WEB (Studi Kasus Universitas Muhammadiyah Sorong). Insect (informatics and Security): jurnal Teknik Informatika, 1(1), 1-8. 